\title{
Malaria control in the municipality of San Esteban, Honduras
}

\author{
Christine Elizabeth Bell, ${ }^{1}$ Laurence Slutsker, ${ }^{2}$ Raymond F. Beach, ${ }^{2}$ \\ Stanley O. Foster, ${ }^{3}$ German Jimenez, ${ }^{4}$ and Maria Elena Sarmiento ${ }^{4}$
}

ABSTRACT Objectives. To assess the burden of malaria in San Esteban, Department of Olancho, Honduras, and provide recommendations for control.

Methods. Malaria causes appreciable morbidity in San Esteban. In 2006, health workers reported an increase in malaria cases and requested recommendations for control. In 2005, 385 cases (Plasmodium vivax, 316; P. falciparum, 69) were detected from 4007 blood smears in the San Esteban laboratory (slide positivity rate $=9.6 \%$ ). During May-July 2006, we assessed the burden of malaria and made recommendations. We reviewed epidemiologic data from slideconfirmed malaria cases in 2005 and 2006 and conducted a knowledge, attitudes, and practices survey in households to assess malaria diagnostic, treatment, and prevention practices.

Results. During May-July 2006, 143 laboratory-confirmed malaria cases were detected (P. vivax, 134; P. falciparum, 9) in San Esteban, compared with 104 (P. vivax, 79; P. falciparum, 25) in May-July 2005. From January 2005 to July 2006, 538 cases were detected in San Esteban, with increased frequency in May-October and the highest incidence in children 0-14 years old. We administered 112 surveys in 19 communities. Seventy percent of respondents reported a history of malaria in a household member, with the highest frequency reported in mothers (45\%) and children under 14 years old (37\%). Most households did not have mosquito protection such as bed nets, screens, or indoor residual insecticide.

Conclusions. Malaria is ongoing in San Esteban, with increased incidence in children. We recommend increased availability and promotion of insecticide-treated bed nets, improved timing and coverage of indoor residual spraying, and improved community malaria practices through education sessions.

Key words Malaria, Plasmodium falciparum, Plasmodium vivax, Honduras.

1980 Breckenridge Drive, Atlanta, Georgia 30345, United States of America. Send correspondence and reprint requests to: Christine E. Bell, 1980 Breckenridge Drive, Atlanta, Georgia 30345, United States of America; e-mail: cebell@sph.emory.edu

2 Malaria Branch, Division of Parasitic Diseases, National Center for Infectious Diseases, Centers for Disease Control and Prevention, 4770 Buford Highway, Atlanta, Georgia 30341, United States of America.

3 Hubert Department of Global Health, Rollins School of Public Health, Emory University, 1518 Clifton Road 712, Atlanta, Georgia 30322, United States of America.

4 Honduras Outreach Incorporated, 4105 Briarcliff Road Northeast, Atlanta, Georgia 30345, United States of America.
Malaria transmission is unstable in Honduras and accounts for $40 \%$ of malaria cases in Central America (1). In 2004, the Pan American Health Organization (PAHO) reported that there were 15689 laboratory-confirmed cases in Honduras, with $95 \%$ due to Plasmodium vivax and 5\% to Plasmodium falciparum infection (2). The northwestern part of Honduras (Departments of Olancho and Colon) accounts for most malaria cases in the country (3). Seasonal malaria transmission occurs in this region and malaria frequency is highest during the rainy season months of May-October (4). The municipality of San Esteban is located in northwestern Olancho and has a population of approximately 21900 inhabitants. San Esteban has historically had the highest malaria incidence in the department of Olancho. During 2005, the municipal laboratory in San Esteban reported 385 positive cases detected from 4007 thick film blood smears. One of the authors has noted that of the 385 laboratory-diagnosed cases in 2005, 316 cases were $P$. vivax and 69 were $P$. fal- 
ciparum (G. Jimenez, March 2006). Malaria cases in San Esteban are recognized through passive case detection by collaborator volunteers (Col-vols) in each community designated for malaria control. The municipal health promoters and Colvols are responsible for taking diagnostic blood smears of community members suspected of being infected with malaria and collaborate with the municipal laboratory in reporting results to patients and administering treatment if indicated.

In spring 2006, health workers from San Esteban reported an increase in $(P$. vivax and $P$. falciparum) malaria cases over recent years and requested public health recommendations for control (5). There was no report of previous malaria investigation in San Esteban and the most recent malaria investigation in Honduras took place in 1997 (6). An investigation was carried out in San Esteban during May-July 2006, which included a review of 2005 and 2006 malaria surveillance data in the San Esteban laboratory and an assessment of malaria-related knowledge, attitudes, and practices (KAP) in the communities through a household survey. The objectives of this investigation were to assess the burden of malaria in San Esteban, to identify areas for improvement in malaria control, and to provide realistic recommendations to the municipality to reduce the impact of malaria.

\section{MATERIALS AND METHODS}

\section{Malaria surveillance data collection}

The 2005 and 2006 malaria surveillance data from the municipal laboratory in San Esteban were reviewed. Data collected from each laboratory-confirmed case included the week of the confirmed laboratory diagnosis, sex and age of the patient, and species of malaria ( $P$. vivax, $P$. falciparum). Data were analyzed to assess weekly incidence, species, and incidence by sex and age group. Age group estimates were based on 2006 population estimates (7). Malaria surveillance data for 2006 were collected through the 28th week of the year, mid-July.

\section{KAP survey}

The household KAP survey was constructed based on previous malariarelated KAP studies that had been conducted in Central America and elsewhere $(8,9)$. Before departure to Honduras, the investigator wrote the survey in English and translated it into Spanish. ${ }^{5}$ Upon the investigator's arrival, the KAP survey was tested with volunteers in a local clinic. The municipal health promoters in San Esteban reviewed the survey as well and made final revisions before field investigation began. KAP survey interviews were conducted during May to July 2006 in households in 19 San Esteban communities. The investigator traveled to communities while working with the municipal health promoters and conducted a survey with one member of each selected household. Convenience sampling was used to select households, due to lack of transportation and available survey time in the communities. One adult member of each selected household provided the responses. The survey included 64 questions, covering demographics, perceptions, and knowledge of malaria, malaria treatment practices, and prevention practices.

\section{Ethical considerations}

KAP surveys were free of personal identifiers so participants were anonymous. All survey participants gave informed verbal consent before administration of each household survey, with the understanding that withdrawal from the survey was possible at any time. Laboratory data were reviewed after identifiers had been removed.

\section{RESULTS}

\section{Malaria surveillance}

The incidences of $P$. vivax and $P$. falciparum infection in 2005 and 2006 were highest during June, July, and August. Figures 1 and 2 display the number of $P$. vivax and $P$. falciparum malaria cases per week for 2005 and 2006, respectively. The 2005 data show year-round occurrence of $P$. vivax cases and increased frequency of $P$. falciparum cases during the summer weeks (the Honduras rainy season occurs during weeks 15-38, April-October). Figure 2 (2006 malaria surveillance data) shows a similar incidence of $P$. vivax cases compared with the previous year. The peak number of cases during week 28 of 2006 represents a malaria outbreak that took place in the community of El Carbon dur-

\footnotetext{
Rafael Flores, professor of global health, Rollins School of Public Health, Emory University, Atlanta, Georgia, United States of America.
}

ing the last week of the malaria investigation. The incidence of $P$. vivax and $P$. falciparum cases in 2005 and 2006 demonstrate that transmission of both species of malaria occur year round. Malaria cases occurred in both children and adults. The incidence of malaria cases in children (ages 0-14 years) was 130.3 cases per 1000 population and for adults (ages 15-64 years) incidence was 79.7 cases per 1000 population.

\section{Household survey results (KAP)}

During May-July 2006, 112 household surveys were conducted in 19 communities in San Esteban. Most household members who participated in the survey were women $(87 \%)$, were age 30 or older $(60 \%)$, were married $(65 \%)$, and had an elementary school level education (75\%). Among KAP survey households, the median number of household members was five and the median number of household rooms was two. Almost all survey participants (95.5\%, 107 people) were aware of the illness of malaria. Forty-six percent who said they had had malaria reported a combination of two or three malaria symptoms, including fever, headache, sweating, and joint pains. Twenty percent of household members responded that they had only fever, and $8 \%$ did not report any malaria symptoms. Most participants interviewed $(69.6 \%)$ reported at least one case of malaria in their house. Household members with the highest frequency of illness reported were mothers (44.9\%) followed by children (37.2\%). According to the 78 participants who reported a history of malaria, most $(67 \%)$ reported waiting 3 or more days before seeking care and treatment.

Several types of health providers were approached for malaria diagnosis and treatment (Figure 3), including the Colvol, municipal community clinics, municipal health promoters, and a local clinic sponsored by a faith-based organization (Honduras Outreach Incorporated) (10). The Col-vol (40.3\%) was the most frequently visited health provider for malaria diagnosis and treatment. Twenty-two percent of KAP survey participants reported receiving treatment from their community clinic, and $26 \%$ reported going to the local clinic sponsored by a nongovernmental organization. Only $6.5 \%$ of household members reported receiving treatment from one of the municipal health promoters and $6.5 \%$ reported going to a clinic in another community. 


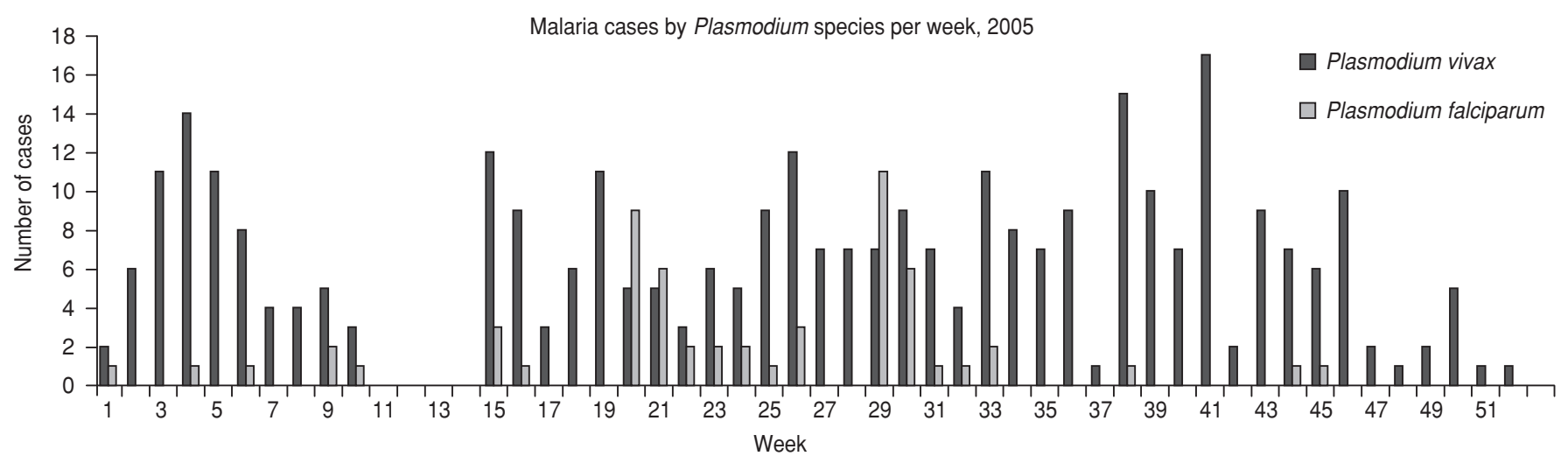

FIGURE 2. Malaria cases in San Esteban, Honduras, 2006 (weeks 1-28)

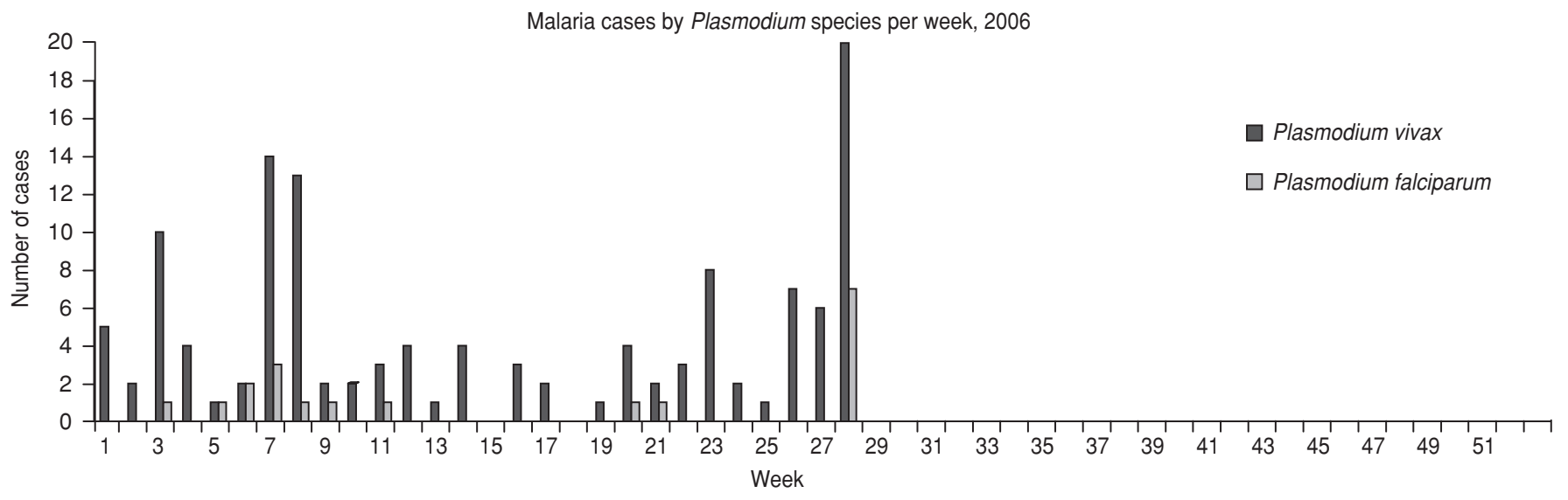

For household practices of malaria therapy (Figure 4), participants reported taking treatment ranging from 0 to 15 days, with the highest frequencies being 5 days ( $47.1 \%$ of KAP survey patients) and 14 days (23.5\%). Figure 4 shows the distribution of days of malaria treatment taken by the KAP participants during malaria illness. Before 2006, the recommended treatment regimen in San Esteban for $P$. vivax infection was 5 days of chloroquine and primaquine. The current recommended regimen is 14 days (25 milligrams (mg) of chloroquine base per kilogram $(\mathrm{kg})$ of body weight divided over 3 days, combined with 0.25 $\mathrm{mg}$ of primaquine base per $\mathrm{kg}$ taken once daily for 14 days) (11).

With regard to household prevention activity, $78 \%$ of households that did not report bed net use reported ever having a history of malaria in at least one household member. In contrast, only $51 \%$ of households that reported bed net use ever had a history of malaria in a household member. Bed net use was associated with decreased odds of reported malaria (odds ratio $0.30,95 \%$ confidence interval $0.13-$ 0.71) (EpiInfo $^{\mathrm{TM}}$ version 3.3.2, Centers for Disease Control and Prevention, Atlanta, Georgia, United States of America).

\section{DISCUSSION}

This investigation demonstrated that malaria is an ongoing public health issue in the municipality of San Esteban. Malaria cases occur year round in San Esteban, with increased frequency of $P$. falciparum during the May-October (rainy season) and the highest incidence in children 0-14 years old. Most households in these communities did not have access to vector control measures, such as insecticide-treated bed nets, indoor residual treatment, and window or door screens. One of the authors has noted that, in Honduras, bed nets are sold in major cities and towns for 120-150 Honduran lempira (national currency), around 8.00 U.S. dollars, and because of this high cost are not highly accessible to these communities (M. E. Sarmiento, July 7, 2006). Moreover, according to lo- cal health promoters, bed nets already treated with insecticide are usually not available and household members must buy and apply the insecticide.

\section{Health-seeking practices}

Most KAP survey participants demonstrated general awareness of malaria and malaria transmission. Most community members reported learning about malaria in their communities and were familiar with the malaria presentations given by the municipal health promoters. However, despite knowing about malaria illness and symptoms, the majority of household members reported waiting 3 or more days before seeking diagnosis and treatment. This delay in seeking malaria care in San Esteban is likely due to a number of factors including household distance from community clinics, opportunity cost, and the system of passive malaria detection in the communities. Given these observations, it is important that there be a more active relationship between the Col-vols and household members. 
FIGURE 3. Health care provider visited for malaria care in San Esteban, Honduras, 2005-2006

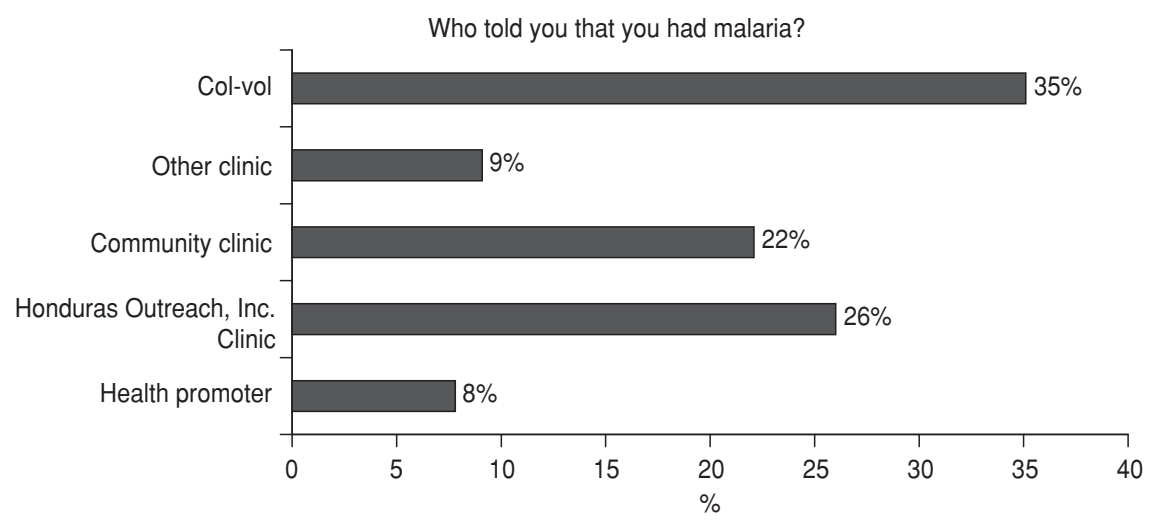

FIGURE 4. Reported days of malaria therapy in San Esteban, Honduras, 2005-2006

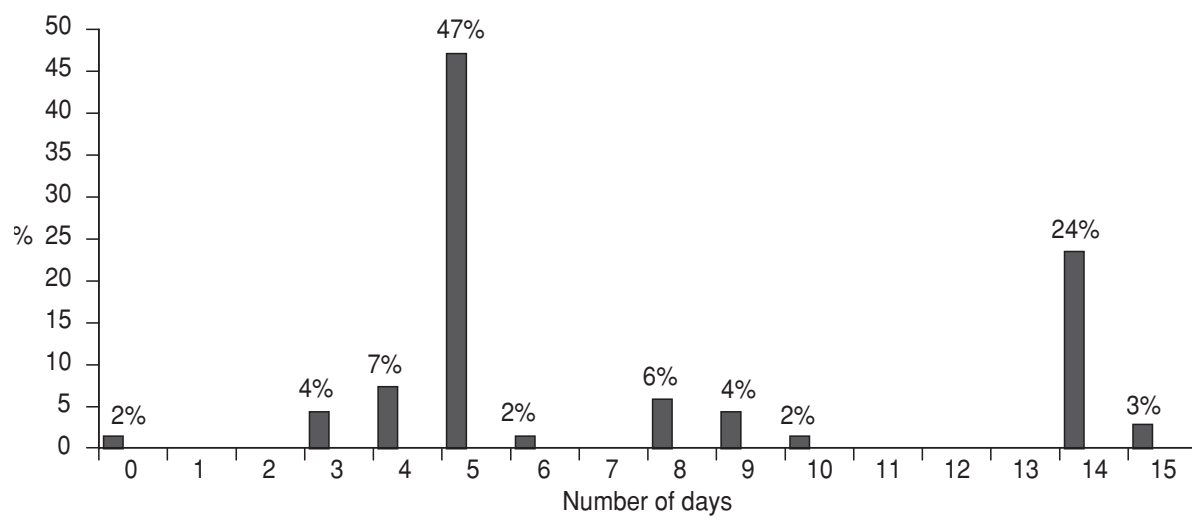

\section{Diagnostic and treatment practices}

A major area identified for improvement involved the diagnostic practices of the Col-vols. Frequently, the Col-vols treated symptomatic community members without taking a diagnostic blood smear, which made identification of malaria cases difficult. To gain a better understanding of the true incidence of malaria, it is important that the Col-vols take diagnostic blood smears before distributing treatment. The Col-vols also serve as the primary malaria surveillance source. If they do not take diagnostic smears or report administration of treatment, the municipal health promoters remain unaware of potential malaria cases occurring and of when to investigate a possible outbreak. Col-vols are also responsible for follow-up of confirmed cases and administration of chloroquine and primaquine. The main improvement needed for malaria therapy in San Esteban is to increase treatment completion rates in the community. The Col-vols also need to ensure that community members take their treatment for the recommended number of days.
This study had a few limitations. During the KAP survey interviews, it was assumed that the reported household histories of malaria illness, diagnosis, and treatment were accurate. Although there is no reason to suspect misinformation was provided, it is possible that respondents overreported malaria-related histories in hope of receiving interventions such as insecticide-treated nets. In addition, the investigation was limited because of a lack of transportation, so a larger number of KAP surveys could not be done. Therefore, it was possible to complete only $56 \%$ of the (200) planned survey interviews.

\section{CONCLUSION AND RECOMMENDATIONS}

Of the San Esteban households interviewed in the study, reported bed net use indicated a protective effect for household history of malaria. Insecticide-treated mosquito nets are associated with decreased severe malaria infection and morbidity in regions with intense and less intense transmission (12). Mosquito nets provide protection against mosquitoes that bite during nighttime hours when people are sleeping, such as the primary mosquito vector in Honduras, Anopheles albimanus (1). Given the low level of individual protection from mosquitoes in San Esteban, increasing ownership and use of bed nets would reduce the public health burden of malaria. Considering the general poverty level in this area of Honduras, providing the insecticide-treated mosquito nets free or at greatly subsidized cost would increase household access. It is also important that health workers train community members in maintaining bed nets and applying insecticide, if pretreated long-lasting nets are not obtained.

Indoor residual spraying is also a major strategy for reducing and interrupting malaria transmission and is one of the main vector-control interventions recommended by the World Health Organization Global Malaria Program (13). Indoor residual spraying is most effective when applied to households before the beginning of seasonal transmission periods, primarily before the start of the rainy season(s) (14). If application of indoor residual spraying can be mobilized, it would be important to base the selection of the insecticide to be used on mosquito susceptibility data in Honduras. Community acceptance of indoor residual spraying treatment and cooperation is also important and requires education and mobilization. Community members should also be engaged in prevention activities such as eliminating standing water and protecting individual households.

In the communities of San Esteban, the Col-vols are responsible for taking diagnostic blood smears, assisting in referrals for care, recording initial patient information, and administering malaria treatment when necessary (15). Given these significant responsibilities, ongoing supervision, support, and evaluation of their activities are important. To ensure quality control among Col-vols in each community, the municipal health promoters could increase supervision and provide feedback for Col-vols on a consistent basis. The Col-vols must also increase their visibility in communities, such as with flags or signs for their houses (16).

In summary, we documented a high rate of laboratory-confirmed infection of malaria in San Esteban. Results from the KAP survey analysis were consistent with a substantial clinical burden, along with opportunities for improvement in prevention, diagnosis, and treatment; community education; and supervision 
and training of volunteer health workers. Addressing these challenges may help to reduce the malaria burden in the communities of San Esteban.

Acknowledgments. We thank the health personnel in the Honduras Outreach Incorporated clinic and the municipal health team in the municipality of

1. Cuesta J, Aviles MV. Socioeconomic aspects of malaria in Honduras: towards an effective agenda. Economic and Sector Study Series. Washington, D.C.: Inter-American Development Bank; 2005.

2. Pan American Health Organization. Table 5a: epidemiological status for 21 countries with active malaria programs. Washington, D.C.: PAHO; 2004. Available from: http://www. paho.org/English/AD/DPC/CD/malstatus-2004.pdf. Accessed 7 October 2006.

3. Pan American Health Organization. Roll back malaria in meso America: malaria situation in countries: Honduras. Washington, D.C.: PAHO; 2000. Available from: http://www. opsoms.org / English / AD / DPC / CD / rbmmesoamerica-hon.pdf. Accessed 7 October 2006.

4. Zhou G, Minakawa N, Githeko AK, Yan G. Association between climate variability and malaria epidemics in the East African highlands. Proc Natl Acad Sci U.S.A. 2004;101(8): 2375-80.

5. Bell, C. Malaria control in the municipality of San Esteban, Honduras, Central America
San Esteban. It was an honor to be able to participate in malaria control with the health promoter team, including activities of prevention, detection, diagnostics, and treatment. The public health services that exist between the communities, volunteer collaborators, health promoters, and health clinics are an excellent public health model for those

\section{REFERENCES}

[master's thesis]. Atlanta, GA: Emory University; 2002.

6. Palmer CJ, Makler M, Klaskala W, Lindo JF, Baum MK, Ager AL. Increased prevalence of Plasmodium falciparum malaria in Honduras, Central America. Rev Panam Salud Publica. 1998;4(1):40-2.

7. Central Intelligence Agency. World factbook: Honduras. Age structure: 2006 estimates. Washington, D.C.: CIA; 2007.

8. Ruebush TK, Weller SC, Klein RE. Knowledge and beliefs about malaria on the Pacific coastal plain of Guatemala. Am J Trop Med Hyg. 1992;46:451-9.

9. Sanjana P, Barcus MJ, Bangs MJ, Ompusunggu S, Elyazar I. Survey of community knowledge, attitudes, and practices during a malaria epidemic in central Java, Indonesia. Am J Trop Med Hyg. 2006;75(5):783-9.

10. Honduras Outreach, Inc. Medical program. Atlanta, GA: HOI; 2006.

11. World Health Organization. Guidelines for the treatment of malaria. Geneva: WHO; 2006. Available from: http://www.who.int/ who work in rural communities worldwide. We thank Dr. Rafael Flores for helping translate the KAP survey to Spanish and all the San Esteban community households for their participation in the KAP survey. This field investigation was partially funded by the Anne and William A. Foege Global Health Fund.
malaria/docs/TreatmentGuidelines2006.pdf Accessed 9 October 2006.

12. Sachs J, Malaney P. The economic and social burden of malaria. Nature. 2002;415(6872):680-5.

13. Roll Back Malaria Department, World Health Organization. Strategic orientation paper on prevention and control of malaria. WHO/ HTM/MAL/2005.1105. Geneva: WHO; 2005.

14. World Health Organization. WHO pesticide evaluation scheme. Pesticides and their application. Geneva: WHO; 2006.

15. Ruebush TK II, Godoy HA. Community participation in malaria surveillance and treatment. I. The volunteer collaborator network of Guatemala. Am J Trop Med Hyg. 1992;46(3): 248-60.

16. Cropley L. The effect of health education interventions on child malaria treatmentseeking practices among mothers in rural refugee villages in Belize, Central America. Health Promot Int. 2004;19(4):445-52.

Manuscript received on 23 January 2008. Accepted for publication on 16 July 2008 .

RESUMEN Objetivos. Evaluar la carga de malaria en San Esteban, departamento de Olancho, Honduras, y ofrecer recomendaciones para su control.

Métodos. La malaria es causa de una considerable morbilidad en San Esteban. En Control de la malaria en el
municipio de San Esteban,
Honduras 2006, los trabajadores sanitarios informaron un aumento de casos de malaria y solicitaron recomendaciones para su control. En 2005, en el laboratorio de San Esteban se detectaron 385 casos (316 por Plasmodium vivax y 69 por $P$. falciparum) en 4007 frotis sanguíneos (tasa de positividad: 9,6\%). Entre mayo y julio de 2006 se evaluó la carga de malaria y se hicieron las recomendaciones. Se revisaron los datos epidemiológicos de los casos confirmados de 2005 y 2006 y se aplicó una encuesta sobre conocimientos, actitudes y hábitos en los hogares para evaluar las prácticas relacionadas con el diagnóstico, el tratamiento y la prevención de la malaria.

Resultados. Entre mayo y julio de 2006 en San Esteban se detectaron 143 casos de malaria confirmados por el laboratorio (134 por $P$. vivax y 9 por $P$. falciparum), en comparación con 104 (79 por P. vivax y 25 por P. falciparum) entre mayo y julio de 2005. Entre enero de 2005 y julio de 2006 se detectaron 538 casos en San Esteban, con un aumento en la frecuencia entre mayo y octubre y la mayor incidencia en niños de 0 a 14 años. Se aplicaron 112 encuestas en 19 comunidades. De los que respondieron, 70\% había tenido algún miembro del hogar con malaria, con una mayor frecuencia en las madres $(45 \%)$ y los menores de 14 años (37\%). La mayoría de los hogares carecían de protección contra los mosquitos, como mosquiteros para las camas y ventanas o fumigación de interiores.

Conclusiones. La malaria se mantiene en aumento en San Esteban, con una mayor incidencia en los niños. Se recomienda incrementar la disponibilidad y la promoción de mosquiteros tratados con insecticidas, mejorar la periodicidad y la cobertura de la fumigación de interiores y mejorar los hábitos de la comunidad mediante sesiones educativas.

Palabras clave Malaria, Plasmodium falciparum, Plasmodium vivax, Honduras. 